\title{
A Continuous Professional Development Strategy for Expanded Competencies Needed by Radiographers Working in Rural Areas
}

\author{
Bernard Mung'omba ${ }^{1} \&$ Annali DH Botha ${ }^{2}$ \\ ${ }^{1}$ KwaZulu-Natal Department of Health, Mosvold Hospital, Ingwvuma, South Africa \\ ${ }^{2}$ Department of Health Studies, University of South Africa, Pretoria, South Africa \\ Correspondence: Bernard Mung’omba, KwaZulu-Natal Department of Health, Mosvold Hospital, Ingwavuma \\ 3968, South Africa. Tel: 27-72-175-7685. E-mail: 37335138@mylife.unisa.ac.za
}

Received: July 27, 2019 Accepted: September 15, 2019 Online Published: November 25, 2019

doi:10.5539/gjhs.v11n13p121 URL: https://doi.org/10.5539/gjhs.v11n13p121

\begin{abstract}
Introduction: The emphasis on Primary Health Care (PHC) with a focus on preventative care offers a challenge for rural radiographers to advance solutions that are change focused. Published evidence suggest that allied health professionals such as radiographers employed in rural areas of South Africa were confronted with an assortment of challenges and responsibilities that demand a wide range of skills and competencies. Additional skills could be essential and Continuous Professional Development (CPD) strategy could be used as a vehicle to equip rural radiographers.
\end{abstract}

Objective: To propose a CPD strategy that may support rural radiographers' expanded and extended competency development needs.

Methods: This research used exploratory sequential study design involving Phase I (qualitative) and Phase II (quantitative) with seven participants and 101 respondents respectively. The CPD strategy development was based on the results from data analysis of both strands. Since strategy development is based on a process of trustworthiness, six evaluators from the clinical and academia were consulted. The evaluators were purposely selected.

Results: A final CPD strategy for rural radiographers was proposed. Results from a mixed method study were used in the process of developing the CPD strategy.

Discussion: Radiographers working in rural areas of KwaZulu Natal (KZN) a province in South Africa are faced with emerging competency need that require both extended and expanded competencies which may be beyond those required for professional registration. This unmet competency needs can be supported by a CPD strategy that is aligned to these competency needs.

Keywords: CPD Strategy, Rural radiographers, competency

\section{Introduction}

The National Development Plan (NDP) -2030 affirms that the South African health system is supported by the values of primary health care (PHC) and the district health system (National Planning Commission, 2018). The move by the South African health care system towards PHC with an emphasis on preventative health care provides a challenge for rural radiographers to advance solutions that can bring change.

In South Africa radiographers are trained at universities and receive a Bachelor's degree or three-year diploma. The Council for Higher Education (CHE) together with the Health Professions Council of South Africa (HPCSA) are responsible for the accreditation and approval of training programmes (degree or diploma). HPCSA approves facilities where student radiographers can do the required practical part of the qualification. There are currently eight universities that are accredited by the HPCSA. The document for approved facilities was updated in the middle of 2018 (HPCSA, 2018). Unfortunately, all accredited universities as well as the facilities for students' practical work are situated in urban areas.

A purpose statement in the document of the South African Qualifications Authority (SAQA) for the radiographers' qualification specifies that after completion of the programme the professional will have: “...knowledge and skills required for the Diagnostic Radiography profession and who has gained experience in applying such knowledge 
and skills in the appropriate workplace context" (SAQA, 2018). In a study by Mung'omba and Botha (2017) it was found that radiographers working in rural areas of South Africa need additional skills such as, but not restricted to, teamwork, skill to do and interpret basic obstetric ultrasound scans as well as leadership and management skills. Inexperienced and younger health professionals especially doctors do often request from these rural radiographers to report on radiographs that are done regularly. It seems as if further training could be essential and CPD could be used as a platform to equip rural radiographers to be able to be competent to function in the rural environment.

The study mentioned above was a mixed methods study and the purpose of this study was to investigate and identify additional core competencies or skills required by radiographers working in rural district hospitals of KwaZulu-Natal (KZN) in order to propose a CPD strategy aimed at rural radiographers (Mung'omba \& Botha, 2017).

A strategy, according to Arthur, Thompson, Stricland and Gamble (2011), is the management action plan for running business and conducting operations. For the purpose of this paper, a CPD strategy shall be defined as a plan with a set of activities that may be implemented in the process of providing CPD learning for rural radiographers. Therefore, the purpose of this CPD strategy is to offer a plan that can be used to provide CPD activities that are focused at maintaining and better addressing the emerging competency and skills needs of rural radiographers, many of which may not have been attained during the basic training. The aim and focus of this paper is then to describe the process that was followed in the development of a CPD strategy proposal aimed at radiographers working in rural areas of South Africa and to present the outcome of the study.

In order to allow healthcare professionals to preserve and attain new knowledge, skills and ethical attitudes on a continuous basis the HPCSA introduced CPD (Van de Venter, Friedrich-Nel, Munro, \&, Peer 2017) Therefore, CPD is directed at assisting health professionals to remain clinically competent and in doing so allows them to deliver quality patient care. Furthermore, CPD plays a significant role in ensuring that health professionals get extra knowledge and skills for expanded and extended roles. This is even more relevant in the context of rural South Africa where only $12 \%$ of doctors and $19 \%$ of nurses practice in these rural settings (Volmink, 2018). According to the same author, corresponding figures for other health professionals such as specialists and allied health professionals are even worse.

Rural radiographers are faced with the need to expand their skills which in many cases are not recognised because many individuals work in urban areas and are not familiar with the specific needs of rural radiographers (Cowling, 2013). This situation underscores the view that the present CPD approach may need to be modified to meet the varying competency and skills needs and aspirations of rural radiographers (Sim, 2010). This research is therefore based on the assumption that that there should be a move towards a CPD design that takes into account not only the requirements of radiographers working in urban setting, but also the competency, skills and changing needs of those radiographers working in rural hospitals.

\section{Research Methodology}

\subsection{Research Methods and Design}

A mixed methods research approach was used, meaning that results of qualitative and quantitative phases were combined (Mung'omba \& Botha, 2017). This research utilised an exploratory sequential study design. In the sequential type of mixed methods research, one form of data offers a base for the collection of another form of data (Onwuegbuzie \& Johnson, 2006). The study problem was first explored in Phase I using qualitative methodology and the data obtained was used in Phase II in which quantitative methodology was used. A focus group interview was used to collect data for the qualitative part of the research (Phase I). After the first phase of the study was completed, a questionnaire was constructed based on the results obtained in this phase. The questionnaire was used in the second part (quantitative) of the study which was a survey. The two phases are elaborated on in the data collection section of this paper. In the final stage of the research, a CPD strategy for rural radiographers working in the province of the study context was formulated and it was informed by results from phases as well as experts who participated in the strategy validation process.

\subsection{The Study Population and Sampling Method}

There are 40 rural hospitals in the province where the study was undertaken. A total of a 150 radiographers were found to be working in these rural hospitals. In this study, a parallel sample relationship was used which means that the sample for the focus group interview in Phase I and survey respondents in Phase II were different but drawn from the same population of interest (Onweugbuzie \& Collins, 2007).

In Phase I, seven participants for focus group interviews were selected using a purposeful sampling method. 
These participants were selected based on the fact that they were working in rural hospitals for 4 years or more and therefore were familiar with the rural setting in which radiographers were working and the unique challenges that are experienced in the same setting. In the quantitative phase of the study a census sample of rural radiographers was used. In a census all units in the population are included in the study (Kasuni 2005). For this study it implied that all the rural radiographers that were not part of the sample that was used for the focus group interview, formed part of the census sample.

\section{Data Collection and Analysis}

\subsection{Phase I}

Eight open-ended questions were used to gather data on rural radiographers' competencies, the roles that were expected from them, the needs they had and their expectations as related to CPD. The focus group interview was recorded. For analysis purposes the services of the professional transcribers were used to transliterate the data of the interviews from voice-recorded format into typescript form. After analysing the data of the focus group interview, the results were then used for the preparation and development of the items in the questionnaire for Phase II of the study.

\subsection{Phase II}

Data were collected using self-administered structured questionnaires that were posted to all potential respondents (Mung'omba \& Botha, 2017). The questionnaire consisted of 14 items. Five four-point Likert scale items dealt with the aspects associated with CPD in rural radiography practice (Table 1 section A). The four-point Likert scale format was used in an attempt to reduce possible respondent manipulation. Nine dichotomous items focused on barriers to accessing CPD and suggestions that might be included in the CPD strategy proposal (Table 1 section B). The questionnaire was pre-tested on eight rural radiographers and changes were made as needed. The statistical software programme used in the entry and analysis of data during the second phase of the study was Microsoft Excel for Windows 2010 and the Epi-Info version 7.1.5.

\subsection{Rigour}

The rigour of this study with two phases was considered according to each strand. The researcher ensured the trustworthiness of the results of the qualitative phase using Lincoln and Guba's criteria (1985) namely credibility, dependability, confirmability and transferability. External and internal validity were considered with regard to the quantitative strand and reliability of the questionnaire as well as data-gathering process were also attended to. A number of writers on mixed methods research support the use of known methods for each of the two approaches (Creswell, 2009; Dellinger \& Leech, 2007; Onwuegbuzie \& Johnson, 2006).

\section{Ethical Considerations}

Approval to conduct the research was obtained from the Provincial Health Research and Knowledge Management Committee of the KZN Department of Health (HRKM 091/13) and the University of South Africa (UNISA) Health Studies Ethics committee (HSHDC/173/2013). A verbal consent was obtained from the focus group participants before the interviews. For the survey respondents, it was mentioned in the covering letter that acceptance and completion of the questionnaire constituted consent by the respondent (Mung'omba \& Botha 2017). To maintain anonymity, focus group participants in Phase I were given fictitious names while Phase II respondents were requested to answer questions anonymously.

\section{Results}

\subsection{Results From Phase I of the Study}

Three major themes emerged from the Phase I data analysis. Out of these three major themes one was related to CPD and was themed: Views of rural radiographers on CPD as a lifelong learning concept. Results of the focus group interviews were significant because they revealed in-depth understandings and opinions with regard to CPD, in the rural radiographers' own words. Some of the participants' direct quotes on CPD aspects are reflected below.

The focus group interview reviewed that rural radiographers felt that the current CPD activities were not relevant to the rural practice. This claim is supported by one participant from the focus group who had this to say with respect to the significance of the CPD activities;

'I think those people who are involved in the CPD programing do not know what should be included in the CPD to cater for rural radiographers.' (Male 31 years, Chief radiographer)

Participants in the qualitative phase of the study further lamented the lack of backing by hospitals in rural areas for the radiographers' to attend CPD activities. One participant had this to say; 
'...the medical manager will tell you that you are just going for CPD points so we are not going to give you transport.' (Female 34 years, Assistant Director: radiographer Grade 1).

Distance was another hindrance for rural radiographers to attend CPD seminars which were always held in urban areas. One study participant said;

... 'they always do them in Durban or Pietermaritzburg and we don't have time to go there.' (Female, 26 years, Radiographer production).

This, to some degree, is a statement of frustration. Radiographers in rural areas are just saying that they want to attend CPD seminars but due to long distances they are unable to attend.

\subsection{Results from Phase II of the study}

The questionnaire was distributed to 135 rural radiographers. Of the 135 respondents, only 101 respondents responded (Tables $1 \& 2)$. Thus a return rate of $74.8 \%(\mathrm{n}=109)$ was achieved. The construct that dealt with the role and meaning of CPD in rural radiography practice, in the study, had a poor reliability (alpha $=0.41$ ) and as such individual items under this construct were described without any combination of items statistics (Table 1).

It must also be stated that due to the negative nature of the statement under item 4, it was re-coded before analysis by inversing the scoring of the categories that is; one (strongly disagree) re-coded as four (strongly agree) while two (disagree) became three (agree) and vice versa.

Table 1. Role and meaning of CPD in rural radiography practice $(\mathrm{n}=101)$

\begin{tabular}{|c|c|c|c|c|c|c|c|}
\hline Item No. & Statement & 1 & 2 & 3 & 4 & Mode & Total \\
\hline \multirow{2}{*}{1} & \multirow{2}{*}{$\begin{array}{l}\text { The CPD seminars include topics that are essentially } \\
\text { relevant to rural radiographic practice }\end{array}$} & 27 & 43 & 18 & 13 & & 101 \\
\hline & & $26.7 \%$ & $42.6 \%$ & $17.8 \%$ & $12.9 \%$ & 2 & $100 \%$ \\
\hline \multirow{2}{*}{2} & \multirow{2}{*}{$\begin{array}{l}\text { The teaching of CPD activities that I have attended so } \\
\text { far have been evidence-based }\end{array}$} & 5 & 23 & 60 & 13 & & 101 \\
\hline & & $5.0 \%$ & $22.7 \%$ & $59.4 \%$ & 12.9 & 3 & $100 \%$ \\
\hline \multirow{2}{*}{3} & \multirow{2}{*}{$\begin{array}{l}\text { I attend CPD activities to increase my professional } \\
\text { competency }\end{array}$} & 3 & 17 & 45 & 36 & \multirow{2}{*}{3} & 101 \\
\hline & & $3.0 \%$ & $16.8 \%$ & $44.6 \%$ & $35.6 \%$ & & $100 \%$ \\
\hline \multirow{2}{*}{4} & \multirow{2}{*}{$\begin{array}{l}\text { I attend } \mathrm{CPD} \text { activities only to accumulate points } \\
\text { required for me to maintain my HPCSA registration }\end{array}$} & 42 & 30 & 23 & 6 & \multirow{2}{*}{1} & 101 \\
\hline & & $41.6 \%$ & $29.7 \%$ & $22.8 \%$ & $5.9 \%$ & & $100 \%$ \\
\hline \multirow{2}{*}{5} & \multirow{2}{*}{$\begin{array}{l}\text { It is the responsibility of the hospital to foster } \\
\text { competency of radiographers through CPD support }\end{array}$} & 6 & 20 & 35 & 40 & \multirow{2}{*}{4} & 101 \\
\hline & & 5.9 & $19.8 \%$ & $34.7 \%$ & $39.6 \%$ & & $100 \%$ \\
\hline
\end{tabular}

The results in Table 1 show that $42.6 \%(n=43)$ of the respondents did not agree with the statement under item number 1 , while $26.6 \%(n=27)$ of the respondents strongly disagreed. This entails that $42.6 \%$ of those surveyed did not believe that the CPD seminars cover topics that are pertinent to rural practice.

Likewise, items number 2 and 3 were ranked 3 - agree by 59.4\% $(n=60)$ of the respondents and $44.6 \%(n=45)$ respectively. This entails that respondents agreed with the statements that the CPD seminars they have been to this far were evidence-based and that they attended these CPD activities to increase professional competency. It is interesting to learn that of those respondents who answered item four, $41.6 \%(\mathrm{n}=42)$ of them strongly agreed with the statement while $29.7 \%(n=30)$ of them indicated 3 - agree (reversed). This suggests that many of the respondents attended CPD events only to collect points required for them to keep their HPCSA registration. This evidence seems to violate the very core value of CPD activities which is to allow all health professionals to maintain and increase their knowledge and skills thereby improving the quality of health care services.

Rural radiographers' work is broad and goes beyond the margins of traditional radiographic duties. Similarly, many of the study respondents $58.6 \%(\mathrm{n}=61)$ in an article by Mung'omba and Botha (2017) expressed worry that the existing scope of practice restricts the role of rural radiographers in the caring of patients. This implies that CPD activities for radiographers working in rural areas must be viewed from a wider perspective that take account of personal, social, health system and political aspects of healthcare in rural areas (Fleet, Kirby, Cutler, Dunikowski, Nasmith, \& Shaughnessy, 2008). 


\subsubsection{Barriers to CPD Activities in Rural Areas}

Rural radiographers are confronted with a wide range of obstacles that may hamper them from accessing CPD activities. Table 2 section A shows that $54.6 \%(n=55)$ of the surveyed respondents reported that hospitals in rural areas do not offer support for radiographers to go to CPD seminars. These results are consistent with other studies which showed that it was more likely problematic to access CPD events such as seminars or other academic gatherings by rural health professionals (Kawooya, 2012). Despite lack of support for rural radiographers towards CPD activities, Hurme (2007) argued that hospitals have a duty to foster competency among its workers including radiographers.

Table 2. Barriers to CPD and suggestions that may be added to a CPD strategy proposal

\begin{tabular}{|c|c|c|c|c|}
\hline & & Yes & No & Total \\
\hline A. & Barriers to CPD & & & \\
\hline \multirow{2}{*}{6.} & \multirow{2}{*}{$\begin{array}{l}\text { Does your hospital provide you with necessary support such as } \\
\text { transport to attend CPD seminars? }\end{array}$} & 46 & 55 & 101 \\
\hline & & $45.5 \%$ & $54.5 \%$ & $100 \%$ \\
\hline \multirow{2}{*}{7.} & \multirow{2}{*}{$\begin{array}{l}\text { Are you discouraged to attend CPD seminars/workshops because of } \\
\text { the distance to where they are held? }\end{array}$} & 74 & 27 & 101 \\
\hline & & $73.2 \%$ & $26.8 \%$ & $100 \%$ \\
\hline & \multirow{2}{*}{$\begin{array}{l}\text { Are you unable to attend CPD seminars because of the shortage of } \\
\text { staff in your x-ray department? }\end{array}$} & 61 & 40 & 101 \\
\hline & & $60.4 \%$ & $39.6 \%$ & $100 \%$ \\
\hline & \multirow{2}{*}{$\begin{array}{l}\text { Are you discouraged from attending CPD seminars because the } \\
\text { topics covered are irrelevant to your rural practice? }\end{array}$} & 37 & 62 & 99 \\
\hline & & $37.4 \%$ & $62.6 \%$ & $100 \%$ \\
\hline & \multirow{2}{*}{$\begin{array}{l}\text { Do you think there is lack of support by rural hospitals for } \\
\text { radiographers to attend CPD activities? }\end{array}$} & 72 & 29 & 101 \\
\hline & & $71.3 \%$ & $28.7 \%$ & $100 \%$ \\
\hline B. & Suggestions to added to CPD proposal & & & \\
\hline & \multirow{2}{*}{$\begin{array}{l}\text { CPD activities must take into account the needs of rural radiography } \\
\text { practice }\end{array}$} & 100 & 1 & 101 \\
\hline & & $99 \%$ & $1 \%$ & $100 \%$ \\
\hline \multirow{2}{*}{12.} & \multirow{2}{*}{$\begin{array}{l}\text { CPD activities must take into account the potential gap between } \\
\text { theory and the actual rural practice. }\end{array}$} & 98 & 3 & 101 \\
\hline & & $97 \%$ & $3 \%$ & $100 \%$ \\
\hline \multirow{2}{*}{\multicolumn{2}{|c|}{ 13. CPD seminars must be rotated so as to include rural areas }} & 100 & 1 & 101 \\
\hline & & $99 \%$ & $1 \%$ & $100 \%$ \\
\hline \multirow{2}{*}{14.} & \multirow{2}{*}{$\begin{array}{l}\text { Each health district health must be responsible for their own CPD } \\
\text { activities. }\end{array}$} & 81 & 20 & 101 \\
\hline & & $80.2 \%$ & $19.8 \%$ & $100 \%$ \\
\hline
\end{tabular}

The distance to which CPD events are held also emerged as an obstacle to rural radiographers attending CPD seminar/workshops. Section A of Table 2 show that $73.2 \%(n=74)$ of the respondents who responded to item 49 were of the view that they are discouraged to attend CPD seminars because of the distance where they are held. These results are consistent with Gawugah, Jadva-Patel and Jackson's (2011) argument that a place where CPD workshops/seminars are held is likely to cause loss of interest by several healthcare professionals.

\subsubsection{Proposals to be Considered During the Development of a CPD Strategy}

Suggestions or ideas as to what the proposed CPD strategy for rural radiographers should cover was sought from the study respondents by means of four dichotomous items (Table 2 section B). Table 2 item 14 shows that $97 \%$ ( $=100$ ) of the surveyed respondents proposed that the CPD strategy should consider including CPD activities that take into account the gap between theory and the actual rural practice. According to the results in Table 3, 80.2\% of the sample indicated that they would favour the idea where each health district was responsible for their own CPD activities. These results are consistent with the DoH's Human Resource for Health strategy which also argues for the development of a system to backs CPD programme in each rural district (Department of Health, 2011). 


\subsubsection{Areas to be Incorporated in the CPD Strategy}

Identified areas to be incorporated in the CPD strategy were derived from the results of data analysis of the two strand study. Table 3 presents a summary of some of the gaps that the study identified and likely remedial actions that may be incorporated in the CPD strategy proposal for rural radiographers.

Table 3. Areas included in the CPD strategy

\begin{tabular}{|c|c|c|}
\hline Element & $\begin{array}{l}\text { Gaps identified from both Phase } \\
\text { I and Phase II of the study }\end{array}$ & $\begin{array}{c}\text { Possible remedial actions to be included in proposed CPD } \\
\text { strategy }\end{array}$ \\
\hline CPD Structure & $\begin{array}{l}\text { Lack of support by hospitals } \\
\text { Shortage of staff } \\
\text { No local CPD programme } \\
\text { coordinators } \\
\text { Lack of involvement of } \\
\text { stakeholders } \\
\text { Impact of CPD not assessed }\end{array}$ & $\begin{array}{l}\text { - Appoint/create positions for CPD programme } \\
\text { coordinators to be based in each rural health district. } \\
\text { - Coordinators to ensure that CPD activities program is } \\
\text { available well in advance so that the radiographers may } \\
\text { have time to plan } \\
\text { - Organise both formal and informal CPD activities } \\
\text { related to ones' work environment } \\
\text { - Involve stakeholders (e.g. doctors, HR, PHC } \\
\text { supervisors and many more). } \\
\text { Include mechanism of evaluating the impact of the } \\
\text { CPD activities. }\end{array}$ \\
\hline $\begin{array}{l}\text { CPD activities } \\
\text { Unmet CPD needs } \\
\text { for rural } \\
\text { radiographers }\end{array}$ & $\begin{array}{l}\text { Most CPD activities not aligned to } \\
\text { rural radiographers' competency } \\
\text { needs. } \\
\text { Available CPD activities mainly } \\
\text { address the needs of radiographers } \\
\text { working in urban environment }\end{array}$ & $\begin{array}{l}\text { - CPD needs assessment: Seek the opinion of rural } \\
\text { radiographers' on topics/areas to be included in CPD } \\
\text { activities } \\
\text { - Include in CPD activities topics of general interest such } \\
\text { as those identified in the current study } \\
\text { - Identify rural radiographers unmet needs } \\
\text { (competencies) that can be addressed through CPD } \\
\text { activities and include them in the CPD plan } \\
\text { Grant currency not just with current or recent rural } \\
\text { practice but also include current technologies in } \\
\text { radiography }\end{array}$ \\
\hline CPD venues & Distance to CPD venues & 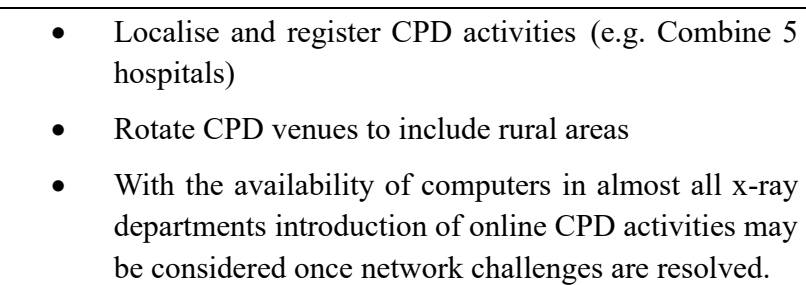 \\
\hline
\end{tabular}

\section{Discussion}

\subsection{Draft CPD Strategy and the Validation Process}

The results from the mixed method study were used to develop a draft CPD strategy proposal (Mung'omba \& Botha, 2017). The basis for developing the draft CPD strategy was to present, before evaluators, critical areas that emerged from that study. Six assessors included two senior radiographers and one senior rural medical officer, all working in rural hospitals and two from the academia. These were purposely selected. This was done to secure a broader representation from both clinical staff and the academics.

\subsection{Process Followed in the Development of the Proposed CPD Strategy}

The process followed in the development of the proposed CPD Strategy is reflected in Figure 1. Development of a strategy may be based on either formal or informal consensus or evidence linked (Thomson \& Dowding, 2006). For this strategy, two methods were employed namely evidence-linked and formal consensus. The use of 
consensus in the development of the CPD strategy is based on the process of consultation which contributes to a trustworthy strategy in the end (Thomson \& Dowding, 2002). The steps in Figure 1 are briefly discussed.

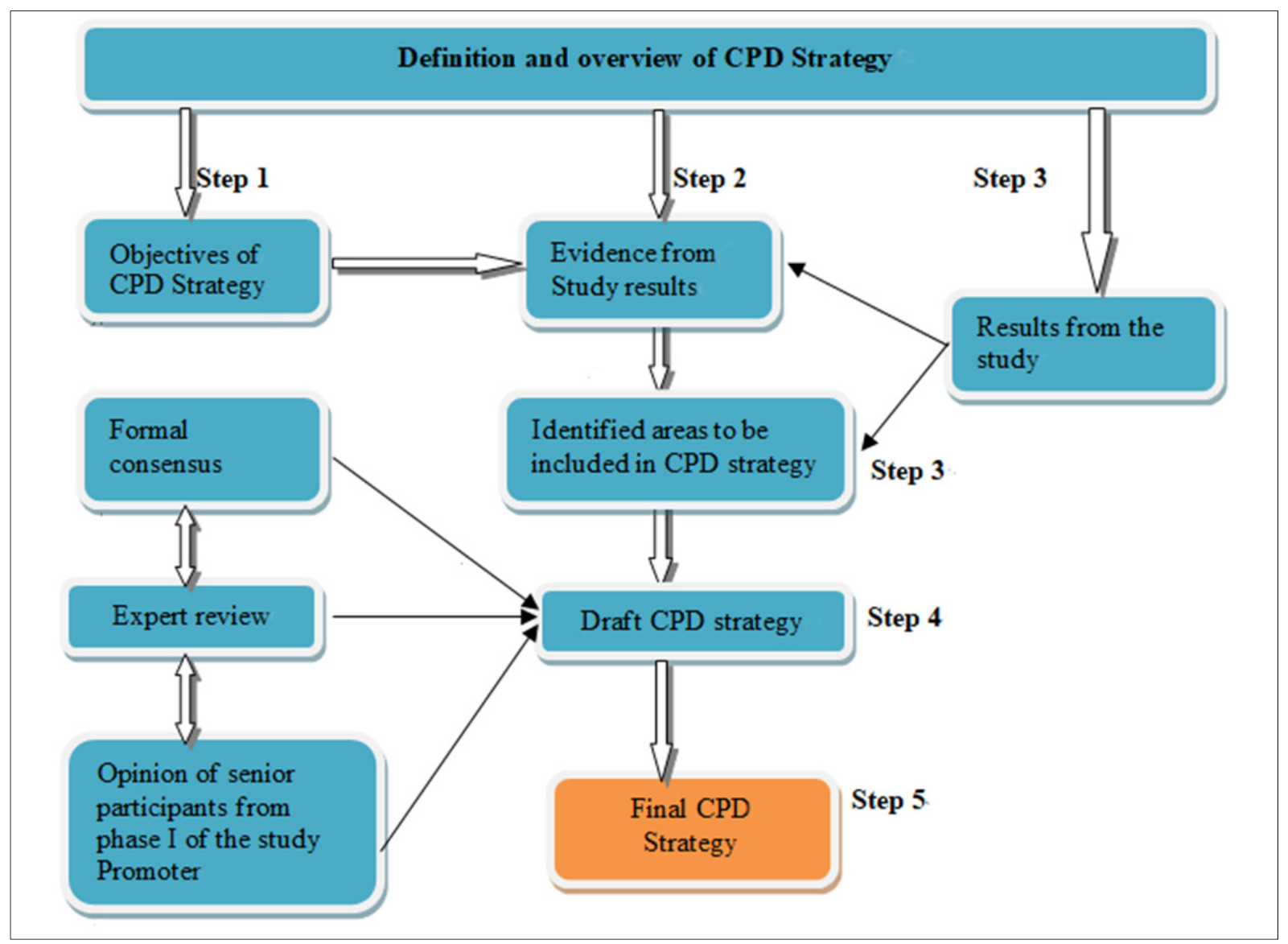

Figure 1. Procedure followed in the development of the CPD strategy for rural radiographers

\subsubsection{Step 1: Proposed CPD strategy objectives}

The Proposed CPD strategy's objectives are:

- To offer CPD activities that are planned to improve competencies that have been identified in the study by Mung'omba and Botha (2017) as essential for rural radiographers but were not covered during the pre-service training.

- To provide CPD activities that will be beneficial to the rural radiographer and also to the service user who happens to be a patient.

\subsubsection{Evidence From the Study}

Step 2 and 3 are presented under sections 5.1 and 5.2 above. In these sections the results from both phases of the study are described.

\subsubsection{Expert Review}

Likert scale scoring based on a four-point scale was used to assess the draft CPD strategy. The assessment instrument and the draft CPD strategy were sent to the evaluators. The evaluators were requested to use the scale and score accordingly if the draft CPD strategy meets the criteria. Evaluators were also asked to provide suggestions and comments where need be. Undertaking the validation process was an effort by the researcher to increase the validity of the CPD strategy and also add to the value of the strategy. The development process of the strategy was also supported by the researchers' own experience in rural radiography practices.

\subsubsection{Feedback From Evaluators}

The demographic characteristics of evaluators of the draft CPD strategy are presented in Table 4. 
Table 4. Demographic information of evaluators of the draft CPD strategy

\begin{tabular}{llll}
\hline No. & Profession & Qualifications & Work Experience \\
\hline 1 & Medical Doctor (District physician) & MBChB, MPH & $15+$ years \\
2 & Assistant Director: Radiographer & Bachelor of Technology: Radiography. & 20 years \\
3 & Chief Radiographer Grade 1 & Diploma in diagnostic radiography & 10 years \\
4 & Radiographer Grade 3 & Diploma in diagnostic radiography & 23 years \\
5 & Academic lecturer (radiography) & Dip. Rad (D), Msc Ultrasound, & 18 years \\
6 & Academic lecturer (radiography) & D. Tech. Radiography & 9 years \\
\hline
\end{tabular}

Feedback received from five evaluators is reflected in Table 5. One evaluator did not reply to the request. Responses of the other five evaluators were taken into consideration when developing the final CPD strategy proposal.

Table 5. Results of the evaluation by evaluators of the draft CPD strategy

\begin{tabular}{|c|c|c|c|c|c|c|}
\hline Criteria & 1 & 2 & 3 & 4 & Mode & Total \\
\hline $\begin{array}{l}\text { Credibility: The CPD strategy is credible and can be trusted } \\
\text { to deliver what it is intended to deliver }\end{array}$ & $\begin{array}{l}2 \\
40.0 \%\end{array}$ & $\begin{array}{l}0 \\
0.0 \%\end{array}$ & $\begin{array}{l}3 \\
60.0 \%\end{array}$ & $\begin{array}{l}0 \\
0.0 \%\end{array}$ & 3 & $\begin{array}{l}5 \\
100 \%\end{array}$ \\
\hline $\begin{array}{l}\text { Relevance: This CPD strategy is appropriate for the target } \\
\text { group (rural radiographers) }\end{array}$ & $\begin{array}{l}0 \\
0.0 \%\end{array}$ & $\begin{array}{l}0 \\
0.0 \%\end{array}$ & $\begin{array}{l}2 \\
40.0 \%\end{array}$ & $\begin{array}{l}3 \\
60 . \%\end{array}$ & 4 & $\begin{array}{l}5 \\
100 \%\end{array}$ \\
\hline $\begin{array}{l}\text { Reliability: The CPD strategy can be used consistently by } \\
\text { rural radiographers }\end{array}$ & $\begin{array}{l}0 \\
0.0 \%\end{array}$ & $\begin{array}{l}3 \\
60.0 \%\end{array}$ & $\begin{array}{l}1 \\
20.0 \%\end{array}$ & $\begin{array}{l}1 \\
20.0 \%\end{array}$ & 2 & $\begin{array}{l}5 \\
100 \%\end{array}$ \\
\hline Implementable: The CPD strategy can be implemented & $0.0 \%$ & $\begin{array}{l}1 \\
20.0 \%\end{array}$ & $\begin{array}{l}0 \\
0.0 \%\end{array}$ & $\begin{array}{l}4 \\
80.0 \%\end{array}$ & 4 & $\begin{array}{l}5 \\
100 \%\end{array}$ \\
\hline Clarity: The CPD strategy is easy, simple and understandable & $\begin{array}{l}1 \\
20.0 \%\end{array}$ & $\begin{array}{l}2 \\
40.0 \%\end{array}$ & $\begin{array}{l}1 \\
20.0 \%\end{array}$ & $\begin{array}{l}1 \\
20.0 \%\end{array}$ & 2 & $\begin{array}{l}5 \\
100 \%\end{array}$ \\
\hline $\begin{array}{l}\text { Sustainability: In its current form the CPD strategy is } \\
\text { sustainable }\end{array}$ & $\begin{array}{l}1 \\
20.0 \%\end{array}$ & $\begin{array}{l}2 \\
40.0 \%\end{array}$ & $\begin{array}{l}2 \\
40.0 \%\end{array}$ & $\begin{array}{l}0 \\
0.0 \%\end{array}$ & 2,3 & $\begin{array}{l}5 \\
100 \%\end{array}$ \\
\hline $\begin{array}{l}\text { Flexibility: The CPD strategy allow flexibility in its } \\
\text { applications and thus can be adjusted to suit the needs. }\end{array}$ & $\begin{array}{l}0 \\
0.0 \%\end{array}$ & $\begin{array}{l}0 \\
0.0 \%\end{array}$ & $\begin{array}{l}3 \\
60.0 \%\end{array}$ & $\begin{array}{l}2 \\
40.0 \%\end{array}$ & 3 & $\begin{array}{l}5 \\
100 \%\end{array}$ \\
\hline
\end{tabular}

Results in Table 5 show that evaluators were consistent in their scoring. This is revealed in the modal score column. However, there were also noteworthy areas that received low rating by evaluators namely clarity and reliability and required attention. For instance, two out of five evaluators noted that the diagrammatic representation of the draft strategy was not clear.

Alterations were made to the diagrammatic representation of the final CPD strategy such as merging of subcomponents and grouping main components into steps (Figure 2). Another area of concern to evaluators was the description of some of the steps of the strategy like step 4 which was considered as not clear and required revision. Based on the views of evaluators, the researcher and the study supervisor reduced the text in the description of the steps of the final CPD strategy. The aim was to improve clarity and to make it easier to read.

Reliability of the strategy was also a concern to the evaluators. Among some of the observations from those evaluator who did not agree was linked to non-representation of rural radiographers in broader management levels. Their concern was that it may be challenging for the strategy to succeed if management is not involved from the beginning. This concern is addressed by including hospital management as part of the stakeholders and also to embolden radiographers to make use of the Extended Management Committees where they sit. 
Sustainability is another area of the draft CPD strategy that received low score. Likewise, evaluators were divided on this criterion. The evaluators who did not agree were of the understanding that there was monetary implication for holding CPD seminars and the strategy did not clearly articulate where funds would come from or indeed how these moneys would be raised. During the development of the final CPD strategy, evaluators' opinions and comments were considered (Figure 2). In the final strategy, for instance, it was proposed that non-governmental organisations and corporations that supply $\mathrm{x}$-ray accessories to the rural hospitals could be approached for support as part of their social responsibilities. Furthermore, it is indicated in the final strategy that home-grown facilitators may be used instead of bringing in facilitators from outside.

\section{The Final CPD Strategy Proposal}

As indicated in Figure 1, step 5 is the last step in the process of developing the CPD strategy. As stated earlier, the final CPD strategy for rural radiographers (Figure 2) was consolidated after receiving the feedback from the evaluators. The CPD strategy includes the key values identified in the study and also opinions and comments from the evaluators. It is proposed that for the CPD strategy to be effectively implemented a process guided by both the main and sub- components must be fulfilled. Steps 1-7 represent the main components which in turn are supported by subcomponents namely stakeholders, local CPD coordinator/s, sustainability and success (Figure 2). These components and subcomponents of the CPD strategy will be explained in more detail to show how the proposed CPD strategy can be implemented.

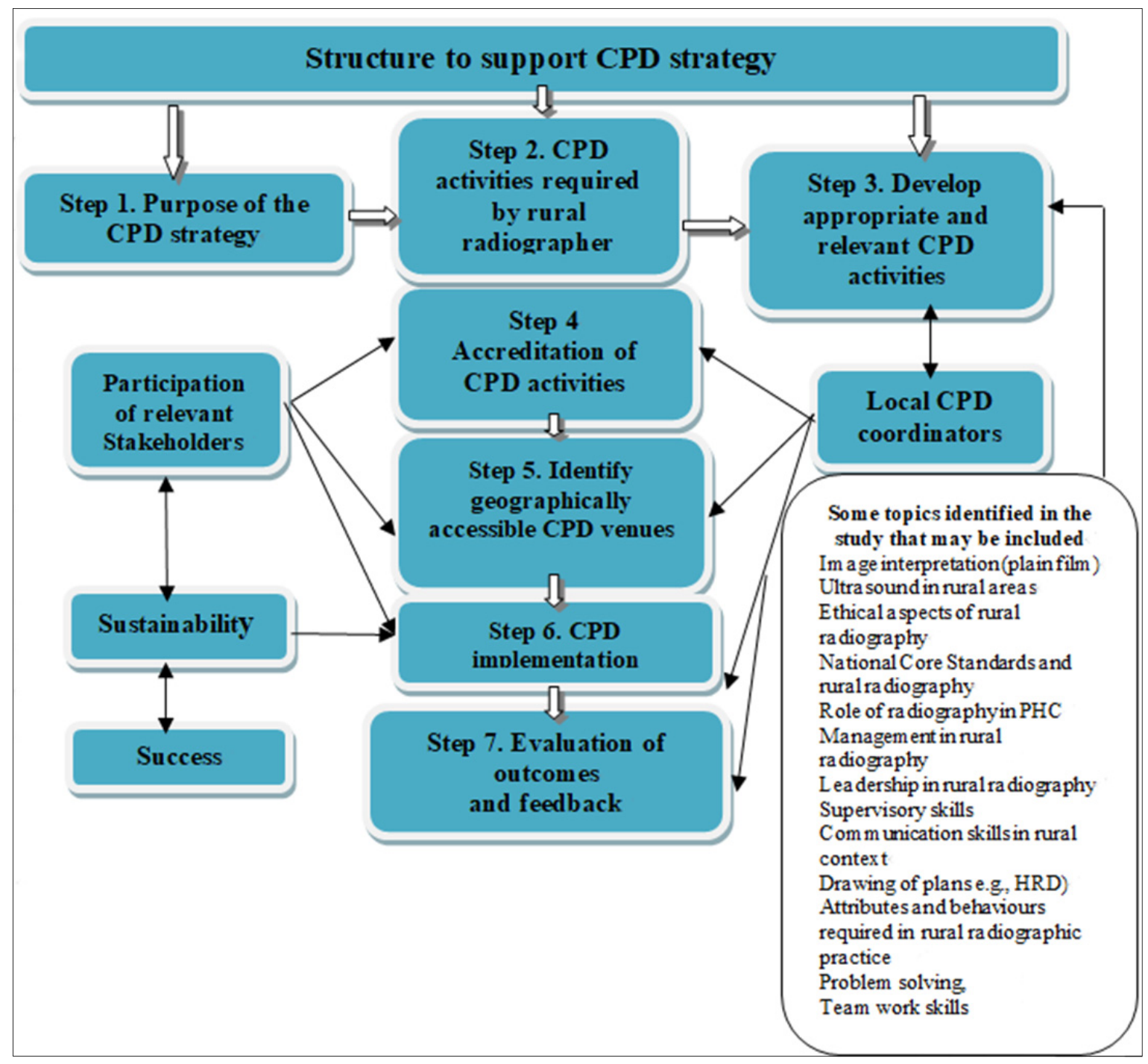

Figure 2. Diagrammatic presentation of the final CPD strategy for rural radiographers working in KZN 


\subsection{Structure of the CPD Strategy}

The CPD structure is based on the gaps reflected in Table 3. The dynamism of rural radiographic practice provides for a CPD strategy that will help keep pace with the ever changing work environment. This entails a CPD strategy, as a plan, which makes available clear guidelines. This CPD strategy is built on a supportive structure that depends on the use of broad stakeholders' participation and existing know-how within and outside the radiography profession. Figure 2 shows the diagrammatic presentation of the proposed CPD strategy.

\subsubsection{Step 1: Aim of the CPD Strategy}

The CPD strategy aims at providing a plan that may be used to offer CPD activities that embrace areas and issues that have been identified in the study as gaps.

\subsubsection{Step 2: CPD Activities Required by Rural Radiographers}

The areas that have been identified in the study are dealt with in Step 2 of the strategy. These have been noted as topics that could be used as appropriate CPD activities for rural radiographers. Other than topics identified in the study it is suggested that the following could be done as a way of identifying more topics:

- Undertake a CPD needs-assessment for rural radiographers

- Use the outcome of CPD needs-assessment as a starting point in the process of developing new CPD activities that are suitable and relevant to rural competency needs.

\subsubsection{Step 3: Develop Suitable and Relevant CPD Activities}

Radiographers in rural areas require to be constantly updated in a number of competency areas due to the diverse nature of rural radiographic practice. Rødahl Thingnes and Lewis (2011) are of the view that this breadth of learning needs can be met by using CPD activities as a catalyst. Step 3, therefore, endeavors to narrow the gap between theory and practice by proposing topics/guidelines that can be used in the context of rural radiography practice.

- Based on the CPD needs assessment, develop CPD activities that are appropriate and relevant to rural radiographers needs. Similarly, Cooke, Couper, \& Versteeg (2011) noted that appropriate and locally based CPD activities were a vital factor in the retention of health professionals.

- Among other things, those at the forefront of developing these CPD activities must guarantee that such activities keep pace with modern practice which must be linked to the responsibilities of radiographers in rural areas.

- Must be mindful that most of the competencies that require updating for rural radiographers are generally generic. But what is clear, though, is that there is usually limited incorporation in the present CPD activities.

- Ensure that radiographers working in rural areas, relevant stakeholders such as doctors, Society of Radiographers of South (SoRSA) and other non-health professionals who work in collaboration with rural radiographers are involved in the development of CPD activities.

- Develop CPD activities for rural radiographers from a wider context that include personal, social, health system and political aspect of rural healthcare (Fleet, Kirby, Cutler et al., 2008).

It must however be emphasised that while the CPD activities should address the specific needs of radiographers working in rural areas, it should not ignore activities that will keep rural radiographers up to date with what is happening in the modern context.

\subsubsection{Step 4: Approval of CPD Activities}

The proposed strategy is established on the foundation of empirical evidence and a process of validation by evaluators and other interested parties.

- The CPD activities must be assessed and registered with relevant accrediting authorities and also involve SoRSA's education committee to ensure credibility.

- Afford a positive collaborative atmosphere with stakeholders to build on existing expertise, and to facilitate links to experts.

- Ensure that development and implementation of a system makes it easy for the target group to access current, appropriate and reliable information that is biased towards their competency requirements. 


\subsubsection{Step 5: Find Geographically Accessible CPD Venues}

Study results show that rural radiographers are discouraged from attending CPD seminars because of distance. In order to mitigate for this challenge, the CPD strategy suggests the following:

- The local CPD programme coordinator may be given responsibilities to liaise with radiographers in order to come up with a consensus on the appropriate venue for all participants.

- CPD programme coordinator may also encourage the introduction of in-house CPD activities and also the use of online activities though this may be a challenge due to connectivity (internet) problems in rural hospitals.

\subsubsection{Step 6: Implementation of the CPD Strategy}

The execution stage will necessitate concerted effort by all rural radiographers and relevant stakeholders. Cooperation between a range of stakeholders is essential to ensure successful implementation process. While the CPD strategy has been developed to attend to a number of extended and expanded competencies that rural radiographers may need or may need to develop during the period of their practice, some may be more pertinent to individual rural areas than others. Based on this, it is proposed that CPD coordinators or any other person may either use the strategy in its totality or just focus on relevant sections that may be applicable to their context.

\subsubsection{Step 7: Evaluation of Outcomes and Feedback}

Evaluation of the outcomes of the CPD strategy is dealt with in step 7. Outcome is described by Muller (2002) as the end results attained at the end of the implementation and completion of the process.

- After implementation, conduct an audit to evaluate whether the strategy was able to meet its objectives.

- The audit can be done annually or any other interval that may be deemed suitable by the radiographers themselves and stakeholders.

- Use cost effective assessment methods.

- Evaluation to be used as a basis for re-planning.

\subsubsection{Subcomponents of the Structure of the CPD Strategy}

The subcomponents the of the proposed CPD structure are equally vital for the successful execution of the strategy.

\subsubsection{Participation of Relevant Stakeholders}

Figure 2 shows that involvement of stakeholders in the process of rural CPD activities is provided for in various steps of the CPD structure. It calls for cooperation between and among the relevant stakeholders. The interested parties might comprise, but not limited to;

- Provincial department of health

- District health officials

- Rural hospital managers

- Other rural health professionals. This will also contribute to teamwork.

- Organisations such as Rural Doctors Association of South Africa (RuDASA) HPCSA, SoRSA, Umthombo Youth Development (UYD)

- Radiography training institutions

Collaboration with these stakeholders can be at any stage of the CPD strategy. These stakeholders may come in as funders of CPD meetings, facilitators and or accreditations of proposed CPD activities. Inclusion of stakeholders also emphasies the concept that radiography in rural areas cannot be practiced in isolation.

\subsubsection{Local CPD Programme Coordinators}

It is suggested that a CPD coordinator be selected from among radiographers in each health district and work on voluntary basis in the same way provincial SoRSA secretariat does.

- Request SoRSA's education committee to help with the training of the coordinators.

- The coordinators will have the duty of arranging venues and networking with authorities and other relevant stakeholders on behalf their rural counterparts.

- The rural health district coordinator should also be part of the process in the development of appropriate CPD activities. What is more, a similar method was adopted in Eastern Cape Province in 2010 and by 
June 2011, according to Cooke et al. (2011) more than 16 fully accredited CPD activities had been undertaken.

\subsubsection{Sustainability of the CPD Strategy}

In the setting of this CPD strategy, sustainability refers to the capacity of the proposal to endure. It was therefore vital to include in the strategy sustainability mechanisms as part of the structure. Sustainability of the CPD strategy hinges on the availability of resources, such as funds for workshops and or seminars, and other logistics. The following could be used to ensure sustainability:

- Consider other funding which may include approaching service providers that supply x-ray equipment and accessories to hospitals for sponsorship.

- Link up with NGOs such as those who offer bursary for rural health professionals such as UYD for support.

- Request other health professionals such as doctors, Human Resource practitioners, Primary Health Care supervisors and other relevant stakeholders to do presentations on subjects that may have a bearing on radiographic practice. The postulation is that if CPD activities are organised locally one is likely to get the services of some of these professionals at no cost.

\subsubsection{Success of the CPD Strategy}

The success of the CPD strategy depends on an attempt to design and develop CPD activities that are inclusive, appropriate and tailored to the requirements of the target group. Therefore, the following will be necessary:

- Ensure that rural radiographers develop a common responsibility of patients' needs and expectations

- Ensure that radiographers working in rural areas feel the ownership of the programme by including them in every step of the process.

- The CPD strategy should not be viewed at in isolation but rather at broader rural health professionals. This is because issues of multi-skilling permeate the wider health setting (White, 2003).

\section{Limitations of the Study}

This strategy is not without limitations. Firstly, there was no available literature for a comparable CPD strategy proposal. Secondly, the evaluators who were used for evaluation and validation of the draft CPD strategy may not have been expert educational tacticians. Thirdly, the proposed CPD strategy was never put into practice and appraised upon implementation.

Despite the limitations outlined above, it is prudent to remind the reader to take into account what the CPD strategy seems to be and assumptions made thereof. Notwithstanding the limitations outlined above, it must be argued that this did not negate the importance and contributions that this CPD strategy could make to the wider knowledge base of radiography.

\section{Recommendations}

- The suggested CPD strategy may not be viewed in isolation but rather at broader rural health professional's setting. This is due to the fact that matters of multi-skilling permeate the broader health environment (White, 2003).

- Rural hospital managers, as representatives of the employer, must work towards assisting rural radiographers to access CPD activities.

- CPD activities can be used towards rural radiographers' on-going career development which is important.

- An online platform can be used deliver some CPD programmes. However, every effort must be taken not to rely on the on-line method alone. This has been shown to sometimes decrease the quality and adds to increased feeling of professional isolation (Remote and Rural Healthcare Educational Alliance, 2010).

\subsection{Future Research}

- A study could be done on the applicability and efficiency of the CPD strategy

- This study may be simulated or used as a departure point for studies focusing on other rural health professionals.

\section{Implications for Rural Radiographers in South Africa}

This CPD strategy offers a structure to support rural radiographers' training and competency development needs. 
The proposed CPD strategy may not be looked at in isolation but rather at broader rural health professional setting. Some CPD programmes can be structured and be delivered online once the challenge of network in rural areas is resolved. It is imperative to note that even though the emphasis of the proposed CPD strategy is on the competency requirements of radiographers in rural areas, the contact between them and their urban counterparts and shared needs should always remain. It is assumed that doing so could serve as an enrichment or an "eye opener" for the radiographers in urban areas if they are invited to attend any of the rural CPD seminars or workshops.

\section{Conclusion}

In view of the gaps in the competencies identified in the study and the perception of CPD activities by radiographers in rural areas, one is bound to recommend that a selfless approach may be needed to sensitise rural radiographers on the benefits one can get from attending CPD seminars. Therefore the authors are of the opinion that this CPD strategy may be the catalyst required for motivating rural radiographers to embrace the benefits of CPD activities in their daily practice. Thus, the CPD strategy could be used as a driver to change the on-going competency development needs for rural radiographers in South Africa. General radiographic competencies alone are not adequate for the development and sustainability of radiographers in rural hospitals. It requires that both the radiographers and their managers admit that expanded and extended competency is the crucial to providing quality healthcare. This may be realised by further developing supportive guidelines that could be used to facilitate the implementation of this CPD strategy.

\section{Acknowledgements}

Authors thank UNISA for the support, the KZN department of health and most importantly rural radiographers who participated in the study

\section{Competing Interests Statement}

The authors declare that there was no financial or conflicting interest that may have influenced the outcome of this study.

\section{References}

Arther, A., Thompson, J. R., Strickland, A. J., \& Gamble, J. E. (2011). Crafting and executing strategy: Creating sustainable high performance in South Africa Text reading and cases (2nd ed.). Beckshire; McGraw-Hill.

Cooke, R., Couper, I., \& Versteeg, M. (2011). Human resource for rural health in South African Health Review of 2011. Durban: Health Systems Trust

Cowling, C. (2013). Global Review of Radiography. Radiography, 19: 90-9. https://doi.org/10.1016/j.radi.2013.01.001

Creswell, J. W. (2009). Research design quantitative, qualitative and mixed methods approaches (3rd ed.). Thousand Oaks, CA: Sage.

Dellinger, A. B., \& Leech, N. L. (2007).Towards a Unified Validation Framework in Mixed Methods Research. $J$ Mix Methods Res., 1(4), 309-332. https://doi.org/10.1177/1558689807306147

Department of Health. (2011). HRH strategy for the health sector 2012/13-2016/17. Retrieved 7th December, 2015, from http://www.gov.za/sites/www.gov.za/files/hrh_startegy_0.pdf

Fleet, L. J., Kirby, F., Cutler, S., et al. (2008). Continuing Professional Development and Social Accountability: a review of the literature. Journal of International Care, 22(S51), 15-29. https://doi.org/10.1080/13561820802028360

Gawugah, J. N. K., Jadva-Patel, H., \& Jackson, M. T. (2011). The uptake of continuing profession development (CPD) by Ghanaian radiographers. Radiography, 17, 332-334. https://doi.org/10.1016/j.radi.2011.07.002

Kawooya, M. G. (2012). Training for Rural Radiology and Imaging in Sub-Sahara Africa: addressing the mismatch between services and population. $J$ Clin Imaging Sci., $2, \quad 37$. https://doi.org/10.4103/2156-7514.97747

Health Professions Council of South Africa. (2018). Professional Board for Radiography and clinical technology: Accredited training facilitie. Retrieved from https://www.hpcsa.co.za/PBRadiography/Education

Hurme, F. E. (2007). Competencies for rural nursing practice (Unpublished doctoral Thesis, Louisiana State University and Mechanical College). Louisiana.

Kasunic, M. (2005). Designing an effective survey. Camegie Mellon University. Retrieved $12^{\text {th }}$ Feb., 2008, from http://www.sei.cmu.edu/pub/ducoments/05.reports/pdf/05hb004.pdf 
Lincoln, Y., \& Guba, E. (1985). Naturalistic enquiry. Beverly Hills CA: SAGE.

Muller M. (2002). Nursing dynamics (3rd ed.). Sandown, Heinemann.

Mung'omba, B., \& Botha, A. D. H. (2017). Core Competencies of Radiographers Working in Rural hospitals of KwaZulu-Natal, South Africa. Afr J Prm Health Care Fam Med., 9(1), a1389. https://doi.org/10.4102/phcfm.v9i1

National Planning Commission. (2018) National Development Plan 2030: Our Future-make it work. Retrieved $20^{\text {th }}$ June, 2018 from https://www.nationalplanningcommission.org.za/Pages/NDP.aspx

Onweugbuzie, A. J., \& Collins, K. M. T. (2007). A Topology of Mixed Methods Sampling design in social science research. Qual Rep., 12(2), 281-316.

Onwuegbuzie, A. J., \& Johnson, R. B. (2006). Validity issues in mixed research. Res Schools, 13(1), 48-68.

Remote and Rural Healthcare Educational Alliance. (2010). Remote and Rural Radiography Report. Retrieved $14^{\text {th }}$ June 2013 from http://www.nes.scot.nhs.uk/rrheal

Rødahl Thingnes, E., \& Lewis, S. J. (2011). Radiographers' experience on learning areas, learning needs and lifelong learning in radiography profession. The Radiographer, 58(1), 9-14. https://doi.org/10.1002/j.2051-3909.2011.tb00139.x

Sim, J. (2010). Continuing Professional Development: Are we at the crossroads? The Radiographer, 57(1), 5-6. https://doi.org/10.1002/j.2051-3909.2010.tb00113.x

South African Qualification Authority. (2018). Registered qualification: Bachelor of Diagnostic Radiography. Retrieved from http://regqs.saqa.org.za/viewQualification.php?id=94832

Thomson, C., \& Dowding, D. (2002). Clinical decision-making and judgment in nursing. London: Churchill Livingstone.

Van de Venter, R., Friedrich-Nel, H., Munro, L., \& Peer, F. (2017). Continuing Professional Development Services and Management structures of the Society of Radiographers of South Africa: a survey and respondents' opinions. S Afr Radiographer, 55(1), 7-13.

Volmink, J. (2018). Reconceptualising Health Professions Education in South Africa. S Afr J Sci, 114(7/8), 1-2. https://doi.org/10.17159/sajs.2018/a0281

White, P. (2003). Establishment of a continuous professional development model for monitoring post-graduate performance of diagnostic radiographers in Hong Kong public hospitals (unpublished PhD Thesis, ong Kong Polytechnic University, Hong Kong).

\section{Copyrights}

Copyright for this article is retained by the author(s), with first publication rights granted to the journal.

This is an open-access article distributed under the terms and conditions of the Creative Commons Attribution license (http://creativecommons.org/licenses/by/4.0/). 